\title{
Acute Drug-Induced Hepatitis during Aripiprazole Monotherapy: A Case Report
}

\author{
Jürgen Kornischka ${ }^{1}$, Joachim Cordes ${ }^{2 *}$, Christina Engelke ${ }^{2}$, Renate Grohmann ${ }^{3}$ and Marcus Agelink ${ }^{1,4}$ \\ ${ }^{1}$ Department of Psychiatry, Psychotherapy and Psychosomatic Medicine at the Klinikum Herford, Germany \\ ${ }^{2}$ Department of Psychiatry and Psychotherapy, Medical Faculty, Heinrich-Heine-University, Duesseldorf, Germany \\ ${ }^{3}$ Department of Psychiatry and Psychotherapy, Ludwig-Maximilian University, Munich, Germany \\ ${ }^{4}$ Clinic of Psychiatry, Psychotherapy and Preventive Medicine, Ruhr-University of Bochum, Germany
}

*Corresponding author: Joachim Cordes, LVR-Klinikum Düsseldorf, Klinik und Poliklinik für Psychiatrie und Psychotherapie, Heinrich-Heine-Universität Düsseldorf, Bergische Landstr. 2, 40629 Düsseldorf, Germany, Tel: 02119223402; Fax: 0211922 2020; E-mail: joachim.cordes@lvr.de

Received date: February 26, 2016; Accepted date: February 29, 2016; Published date: March 07, 2016

Copyright: (c) 2016 Kornischka J, et al. This is an open-access article distributed under the terms of the Creative Commons Attribution License, which permits unrestricted use, distribution, and reproduction in any medium, provided the original author and source are credited.

\begin{abstract}
Only a few case studies have been reported about antipsychotic-induced hepatitis for second generation antipsychotics. A 52-year old patient with recurrent schizoaffective psychosis was switched over from clozapine to aripiprazole monotherapy. Six weeks afterwards the otherwise asymptomatic patient presented herself with skin and scleral jaundice. Hepatic laboratory parameters and liver histological evaluation were initiated. Blood tests performed in outpatient clinic revealed significantly pathological hepatic laboratory parameters (total bilirubin $17.9 \mathrm{mg} / \mathrm{dl}$, direct bilirubin $9.0 \mathrm{mg} / \mathrm{dl}$, GOT $1613 \mathrm{U} / \mathrm{l}$, GPT $2585 \mathrm{U} / \mathrm{l})$. The liver histological evaluation shows a portal inflammatory cellular reaction with eosinophilia. After immediate discontinuation of aripiprazole medication, the elevated laboratory parameters normalised. We assume that the patient had suffered drug-induced hepatitis with predominant cytolysis. This is the first case of aripiprazole-induced hepatitis described in the literature.
\end{abstract}

Keywords: Hepatitis; Hepatotoxicity; Idiosyncratic reaction; Aripiprazole; Antipsychotics; Schizoaffective psychosis

\section{Introduction}

Aripiprazole is a second-generation antipsychotic with partial D2 and 5-HT 1A receptor antagonist and 5-HT 2A receptor agonist effects [1]. It is metabolised in the liver by dehydrogenation, hydrox-ylation and $\mathrm{N}$-dealkylation with the participation of the cytochrome isoenzymes CYP 2D6 and CYP 3A4. The elimination half-life averages out at 75 hours [2].

Liver damage can be induced toxically or idiosyncratically. The primarily dose-dependent toxic dam-age usually occurs immediately. As a result of inadequate drug detoxification, biotransformation can bring about toxic intermediates or end products which can then directly damage the hepatocytes or ductal cells of the bile ducts. Doseindependent idiosyncratic injury (of allergic-immunological or metabolic type) can appear after a latency period of several weeks to months. Such damage usually only concerns patients who have specific hypersensitivity. Amongst classical antipsychotics, tricyclic substances are particularly at risk of being hepatotoxic. Amongst secondgeneration antipsychotics, liver dysfunction is known in particular for olanzapine, quetiapine and risperidone. Regarding anti-psychoticinduced hepatitis, only a few case studies have been reported for the second generation antipsychotics. These have mainly concerned clozapine, risperidone and olanzapine [3-8]. After dose reduction (with toxic damage), or discontinuation of the drug (with idiosyncratic damage), severe hepatic damage is usually reversible.

\section{Case Report}

A 52-year old female patient with a 17 year-long recurring schizoaffective psychosis (ICD-10 F25.0) had already undertaken inpatient psychiatric treatment. On 22 separate occasions she had little insight into the disease, was very incompliant and usually discontinued medication within a few weeks of her hospital stay. Over 15 years she consistently refused to undergo a psychiatric outpatient treatment. One problem was that with both classical and atypical antipsychotics, she sometimes reacted with severe extrapyramidal side effects and often had to suffer severe and prolonged states of acathisia. During the first 15 years of her illness she took a variety of different antipsychotics (haloperidol, benperidol, bromperidol, fluphenazine, flupentixol, zuclopenthixol, perazine, zotepine, risperidone, amisulpride, olanzapine, and quetiapine). She also took a number of mood stabilisers (lithium, carbamazepine, oxcarbazepine, valproic acid). Notable changes in liver enzymes, however, were not observed.

Over 20 years the patient always underwent phases of increased alcohol consumption. During her drinking episodes she consumed an average of $70 \mathrm{~g}$ of alcohol per day. In times of higher consump-tion she even consumed $130 \mathrm{~g}$ of alcohol per day. However, during abstinent periods the patient did not suffer from vegetative withdrawal symptoms. Despite the intermittently increased alcohol con-sumption her transaminase levels generally lay within the normal reference range. She smoked 20 cigarettes a day. She had a body mass index of $26,4 \mathrm{~kg} / \mathrm{m}^{2}$. Other organic diseases were excluded. She did not receive other medication except the psychopharmacological drugs.

After hospital stay in which she was switched over to monotherapy of clozapine, the patient finally managed to comply as an outpatient with this medication for a period of 18 months without any re-lapses. Also, she and others reported no phases of higher alcohol 
consumption, as could be confirmed by CDT tests. When the patient was discharged to outpatient care with $250 \mathrm{mg}$ of clozapine, her transaminase levels were within the reference range (GOT 6 U/l, GGT $6 \mathrm{U} / \mathrm{l}$, GGT $8 \mathrm{U} / \mathrm{l})$. However, during the first six months under clozapine therapy her transaminase levels increased slightly (GOT 80 U/l, GPT 65 U/l, GGT 115 U/l). The following year, the patient on her own volition had gradually decreased the doses of clozapine from 250 $\mathrm{mg} / \mathrm{d}$ to $50 \mathrm{mg} / \mathrm{d}$. She was worried by her increased liver parameters, signs of fatigue, low blood pressure, dizziness, increased salivation and constipation. In addition, she had gained $12 \mathrm{~kg}$ of weight over a year. Ultimately she ceased taking the clozapine medication altogether.

One week later, the patient was switched to $7.5 \mathrm{mg} / \mathrm{d}$ aripiprazole. Before switching she had slightly elevated liver enzymes (GOT $58 \mathrm{U} / \mathrm{l}$, GPT 52 U/l, GGT 150 U/l). Two weeks later, the dose was in-creased to
$10 \mathrm{mg} / \mathrm{d}$ aripiprazole. Six weeks after switch, the otherwise asymptomatic patient presented herself to outpatient department with skin and scleral jaundice in the absence of any pruritus. Otherwise the physical examination produced no pathological findings. Blood tests performed in the outpatient clinic revealed significantly pathological hepatic laboratory parameters (total bilirubin $17,9 \mathrm{mg} / \mathrm{dl}$, direct bilirubin $9.0 \mathrm{mg} / \mathrm{dl}$, GOT $1613 \mathrm{U} / \mathrm{l}$, GPT $2585 \mathrm{U} / \mathrm{l}$, GGT $138 \mathrm{U} / \mathrm{l})$. The coagulation parameters were normal apart from a marginal initial TPT (Quick Value of 68\%) (Table 1). Both cholinesterase values were within the reference range. The aripiprazole medication was discontinued and the patient was monitored in intensive care where she received parenteral nutrition, lactulose and ornithine aspartate. The patient developed no fever, had no rash and showed no signs of an allergic reaction.

\begin{tabular}{|l|l|l|l|l|l|l|l|l|l|l|l|l|}
\hline Day & $\mathbf{1}^{*}$ & $\mathbf{2}^{* *}$ & $\mathbf{4}$ & $\mathbf{7}$ & $\mathbf{8}$ & $\mathbf{9}$ & $\mathbf{1 1}$ & $\mathbf{1 4}$ & $\mathbf{1 9}$ & $\mathbf{2 1}$ & $\mathbf{3 1}$ \\
\hline Total Bilirubin (mg/dl) & 17.9 & 17.36 & 14.45 & 11.95 & 8.69 & 7.99 & 5.21 & 4.39 & 3.4 & 2.6 & 2.4 \\
\hline GOT (U/L) & 1613 & 1345 & 1068 & 684 & 435 & 393 & 291 & 163 & 67 & 40 & 38 \\
\hline GPT (U/L) & 2585 & 2285 & 1744 & 994 & 721 & 695 & 498 & 333 & 124 & 81 & 42 \\
\hline GGT (U/L) & 138 & 130 & 111 & 122 & 153 & 198 & 190 & 122 & 72 & 57 & 35 \\
\hline INR & - & 1.23 & 1.23 & - & 1.19 & 1.08 & 1.01 & 0.92 & 0.97 & - & - \\
\hline PT(sec) & - & 30 & 30 & - & 34 & 31 & 34 & 35 & 30 & - & - \\
\hline Quick value (\%) & - & 68 & 68 & - & 72 & 85 & 102 & 119 & 106 & - & - \\
\hline "Outpatan & - & & - & & & & & & \\
\hline
\end{tabular}

"Outpatient, "*Hospitalisation, International Normalized Ratio (INR), Aspartate Aminotransferase (ASAT/ GOT), Alanine Aminotransferase (ALAT/GPT), GammaGlutamyltransferase (GGT), Units/Liter (U/L), Prothrombin time (PT).

Table 1: Progress of hepatic function after discontinuation of aripiprazole.

Comprehensive investigations (abdomen sonography, abdomen-ct, $\mathrm{X}$-Ray of the chest, oesophago-gastroscopy) revealed no further indicatory findings. There was no sign of infection with hepatotropic viruses, or of primary biliary cirrhosis, primary sclerosing cholangitis or autoimmune hepatitis. Histological evaluation of liver biopsies revealed signs of a portal inflammatory cellular reaction with eosinophilia and evidence of significant moderate cholestasis compatible with drug-induced hepatitis with predominant cytolysis. The patient recovered relatively well physically and within four weeks the elevated laboratory parameters had largely returned to normal (Table 1). Within 6 weeks bilirubin was normalized (Figure 1).

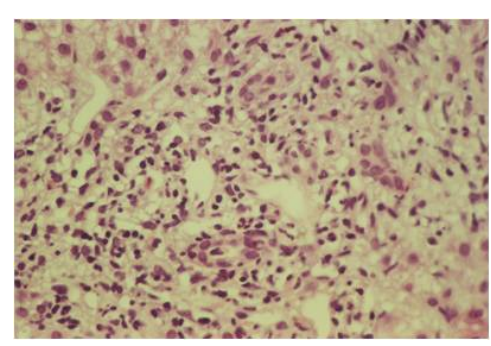

Figure 1: The histological evaluation of liver biopsies - Liver biopsies $3 \mathrm{~cm}$, portal inflammatory cellular reaction with eosinophilia, hematoxylin and eosin stain.

\section{Discussion}

Clinical course and extensive internal medical diagnostics led us to assume that the patient had suffered drug-induced hepatitis with predominantly cytolysis. This was most likely an idiosyncratic reaction probably of metabolic origin following six-week aripiprazole exposure. The liver metabolism may have been compromised by alcohol abuse and previous treatment with clozapine. During the previous 15 years of different psychopharmacological antipsychotic and mood stabilizing treatments, there were no increases of liver values.

\section{Conclusion}

To our knowledge, this is the first case of an aripiprazole-induced hepatitis which in this case directly followed a switchover from clozapine to aripiprazole. Animal studies have shown that the combina-tion of aripiprazole with the Cyp3A4 inhibitor fluvoxamine induces increase in transaminases and as such provides a further indication for a possible hepatotoxic effect of this substance [9].

\section{Acknowledgement}

JC has participated in speakers bureaus for Janssen-Cilag, Eli Lilly, Alpine-Biomed and has received grant/research support from Eli Lilly, Janssen-Cilag, and Pfizer. 
Citation: Kornischka J, Cordes J, Engelke C, Grohmann R, Agelink M (2016) Acute Drug-Induced Hepatitis during Aripiprazole Monotherapy: A Case Report. J Pharmacovigil 4: 201. doi:10.4172/2329-6887.1000201

Page 3 of 3

\section{References}

1. Swainston Harrison T, Perry CM (2004) Aripiprazole: a review of its use in schizophrenia and schizoaffective disorder. Drugs 64: 1715-1736.

2. Mayer B, Bomar D (2004) Blickpunkt Aripiprazol. Verlag: Aesopus.

3. Dumortier G, Cabaret W, Stamatiadis L, Saba G, Benadhira R, et al (2002) Hepatic tolerance of atypical antipsychotic drugs. Encephale 28: 542-551.

4. Bender S, Grohmann R, Engel RR, Degner D, Dittmann-Balcar A, et al (2004) Severe adverse drug reactions in psychiatric inpatients treated with neuroleptics. Pharmacopsychiatry 37: S46-S53.

5. Erdogan A Kocabasoglu N, Yalug I, Ozbay G, Senturk H (2004) Management of marked liver enzyme increase during clozapine treatment: a case report and review of the literature. Int J Psychiatry Med 34: 83-89.
6. Llinares Tello F, Prats Hernandez Prats C, Bosacoma Ros N, Perez Martinez E, Climent Grana E, et al. (2005) Acute cholestatic hepatitis probably associated with risperidone. Int J Psychiatry Med 35: 199-205.

7. Ozcanli T, Erdogan A, Ozdemir S, Onen B, Ozmen M, et al. (2006) Severe liver enzyme elevations after three years of olanzapine treatment: a case report and review of olanzapine associated hepatotoxicity. Prog Neuropsychopharmacol Biol Psychiatry 30: 1163-1166.

8. Wright TM, Vandenberg AM (2007) Risperidone- and quetiapineinduced cholestasis. Ann Pharmacother 41: 1518-1523.

9. Shastry CS, Shafeeque AA, Ashwathnarayana BJ (2013) Effect of combination of aripiprazole with carbamazepine and fluvoxamine on liver functions in experimental animals. Indian J Pharmacol 45: 121-125. 